\title{
Organizational Integration and its Impact on the Effectiveness of Operational Processes (A Case Study on Hikma Pharmaceuticals)
}

\author{
Ayyoub. A. Alsawalhah ${ }^{1}$ \\ ${ }^{1}$ World Islamic Sciences and Education University, Faculty of Business and Finance, Jordan \\ Correspondence: Dr. Ayyoub. A. Alsawalhah, World Islamic Sciences and Education University, Faculty of \\ Business and Finance, Jordan.
}

Received: May 18, 2020

doi:10.5539/mas.v14n7p26
Accepted: June 8, 2020

Online Published: June 10, 2020

URL: https://doi.org/10.5539/mas.v14n7p26

\begin{abstract}
This study aimed to identify the effect of organizational integration (cultural integration, leadership authority integration, functional integration, and structural integration) on the effectiveness of the operational processes (the effectiveness of the strategic plan, the effectiveness of resources and technologies, the effectiveness of performance and results) in the global pharmaceutical company, Hikma Pharmaceuticals. The researcher used the descriptive and analytical method and represented the study population in all Hikma Pharmaceuticals employees. The total number of included 520 administrative employees, the study sample consisted of 129 workers. The study concluded that the level of importance of organizational integration and the effectiveness of operational processes was high. Furthermore, it found that there is an effect of organizational integration in all its dimensions on the effectiveness of the operational processes at the company. The study recommended that Hikma Pharmaceuticals should work on building a comprehensive strategy for organizational development and integration, in addition to developing an integrated plan for developing the operational processes in the company.
\end{abstract}

Keywords: organizational integration, effectiveness of operational processes, Hikma Pharmaceuticals Pharmaceutical Company

\section{Introduction}

Organizational integration is considered one of the most important constituents that guarantees the organization, its balance, and the development of conditions for its effectiveness and efficiency, regardless of its size, location, or nature of activities. This requires the systematic creation or re-engineering of the organization, meaning the mobilization of its composition components should not arise as a result of random or improvised mobilization as it occurs in the minds of the main stakeholders. Instead, it should be as an expression of the outcome of systemic processes that identify the elements on which the organization is formed and builds its capacity (Alsawalhah, 2014). Afterwards, it should then work to link, organize, and evaluate these elements according to the rules and standards that ultimately ensure that they are formed in their integrated, balanced, and adaptive form that function effectively. The real challenge for all business organizations is the ability to build themselves a systematic structure that ensures that their balance is achieved dynamically, does their movement, and guarantees the conditions for survival and advancement. Operations are inseparable with all their requirements from the overall structure of the organization but are related to it (Assaf \& Alsawalhah, 2013), and represent the true expression of the performance of its functions, and this study will focus on researching the elements of the general integration of Hikma Pharmaceuticals, studying its reality, and working to reach the results that executives have been able to upgrade their organization, its resources and operational capacity, as they outline their strategies.

\section{The Problem of the Study and Its Questions}

The requirement to improve the effectiveness of the operational processes in Hikma Pharmaceuticals is a real challenge for management and employees, alike. It is a very complex task and needs to achieve necessities, build diverse and interlocking capacities, and most important attain the requirements of the regulatory integration that guarantees its unity and balance, and thus effective operational processes. The officials understood the importance of this and as a result, this study came to provide possible solutions that will enable them to know the reality of their company and its operational processes. 


\section{The Study Questions}

- What is the reality of applying organizational integration in Hikma Pharmaceuticals?

- What is the reality of the level of effectiveness of Operational Processes in Hikma Pharmaceuticals?

- What is the effect of organizational integration on the effectiveness of Operational Processes in Hikma Pharmaceuticals?

\section{Study Objectives}

- To learn about the reality of organizational integration in Hikma Pharmaceuticals.

- Recognize the reality of the effectiveness of operational operations in Hikma Pharmaceuticals.

- Identify the effect of organizational integration on the effectiveness of operations in Hikma Pharmaceuticals.

\section{The Importance of the Study}

This study will provide a scientific and practical framework as it will provide an integrated model of organizational integration for any organization. It will also help management consultants and researchers as they design their strategies for organizational development or restructuring, both scientifically and systematically. The study will also provide a set of recommendations that will enable the companies to develop their organizational development strategies and improve the operational processes that regulate the work.

\section{The Study Hypotheses}

\subsection{H01: Main Hypothesis}

There is no statistically significant effect at the level of significance $(\alpha \leq 0.05)$ of organizational integration (cultural integration, leadership authority integration, functional integration, structural integration) On the effectiveness of operational processes (strategic effectiveness, resource and technology effectiveness, the effectiveness of Performance and results) in Hikma Pharmaceuticals.

\subsection{Sub-assumptions}

H01-1: There is no statistically significant effect at the level of $(\alpha \leq 0.05)$ of cultural integration on the effectiveness of operational processes in Hikma Pharmaceuticals.

H01-2: There is no statistically significant effect at the level of $(\alpha \leq 0.05)$ for leadership authority integration on the effectiveness of the operational processes in Hikma Pharmaceuticals.

H01-3: There is no statistically significant effect at the level of $(\alpha \leq 0.05)$ for functional integration on the effectiveness of operational processes in Hikma Pharmaceuticals.

(H01-4): There is no statistically significant effect at the level of $(\alpha \leq 0.05)$ of structural integration on the effectiveness of performance and results in Hikma Pharmaceuticals.

\section{The Methodology and Tools of the Study}

The study is based on both descriptive and analytical approaches. The sources of its data are academic references and the information obtained from the questionnaire is designed for this purpose. The respondents of the survey are represented by 520 employees of Hikma Pharmaceuticals, in addition to a random sample of 145 workers. A total of 138 questionnaires were recovered, 129 of which were analyzed after excluding 9 questionnaires as they were not suitable for analysis.

\section{The Theoretical Framework}

\subsection{Organizational Integration}

A scientific understanding of the meaning of the system is closely related to the objective understanding of the term organizational integration. If we understand the system as an expression of that whole, which consists of some elements that are identified, collected and linked together according to specific laws and scientific rules while performing a specific job performance. Therefore, organizational integration becomes an expression of the organization determining its components by aright ways, ensuring that these elements are defined holistically, and linking all these elements and components through normative foundations, by agreed laws and organizational rules. This ensures that the organization is formed in a balanced and uniform manner (Assaf, 2014), (Colquit, 2018). This understanding leads to an important observation: that no entity can form anything, or any organization, in the form of a system, if prior knowledge of the laws and scientific rules of this system is not completed (Assaf, et al, 2013). This is what all organizations, either regional or international, suffer from 
their various names and activities. The reason being is that there is no scientific agreement on the laws and organizational rules that are based on a clear vision, so administrative thought is made abundant theoretical contributions. However, it is nothing more than mere jurisprudence and personal opinions that do not rise to the level of scientific laws. The reality of the situation in these organizations is that they are composed of the mobilization of elements selected in diligent ways and depends on their quality and level on the financial status, rather than a holistic, integrated approach. (Assaf, 2014), (Ash \& Kay, 2012).

\subsubsection{Dimensions of Organizational Integration}

Organizational integration is defined in four major dimensions: (Assaf, 2014), (Bartlett, Goshal, 1994, 223-225).

First: Cultural Integration: The state of organizational integration is not achieved automatically, nor is it merely an invitation to work with it, nor by providing the necessary technical arrangements for it. Rather, there must be cultural requirements and transformations within the concerned organizations that seek to implement the management model effectively, so that a kind of autism or cultural harmony occurs between the culture of the organization's authority, the culture of management it administers, and the culture of its employees. (Kehinde, 2012) and (Richard, 2008) concludes that there may be multiple definitions that we find about the term culture, and despite this plurality, they do not differ from each other substantially. Rather, the formal difference is mostly due to the terms used by each researcher, or to the degree of overall or detail through which concepts are presented (Alsawalhah, 2014). One of the most common definitions that are usually provided is the definition of Edward Taylor, where he says, "It is that whole complex that includes knowledge, beliefs, arts, ethics, law, custom and habit, and other capabilities that a person acquires as a member of society" (Thompson et al., 1997). One of the modern sociologists, Robert Birsted, defines it as "that whole complex that consists of everything we think, do, or possess as members of society." (Thompson et al., 1997, 23). Meanwhile, Horton One Hunt defines it as an "integrated system of social behavior backed by some principles, ideas, and values." (Thompson et al., 1997, 20-24).( Thompson et al.) defines it as "the compound that combines three concepts: cultural prejudices (shared values and beliefs), social relationships, and patterns and lifestyles". (Thompson et al., 1997, 27). We do not find among these definitions what can be considered a comprehensive and clear definition in a way that calls us to adhere to and adopt it. Even though each of them has highlighted some of the basic variables necessary to build the full definition, particularly the definition of Thompson and his co-authors. To precisely define Cultural Integration, we find that culture is a holistic system that consists of the interaction of three basic sub-systems: (Assaf, 2014).

- The system of values and beliefs embraced by individuals and groups. When we talk about the culture of society, the meaning of the value system in the first place becomes those values that the ruling authority embraces in society. Meanwhile, when we talk about the culture of the organization, the value system becomes in the first place those values that the authority of the organization adopts, and that regardless of the existence of some different value systems in some individuals or groups within the community or organization. The intended culture is the dominant culture, and it is the dominant culture of power. (Geurts, 2008,145).

- The knowledge system acquired by individuals and groups as a result of continuous interaction with the environmental surroundings. This system includes all the information, principles, general rules, scientific theories, and concepts related to the various phenomena that are dealt with.

The system of skills and experiences in all their forms and social types (such as customs and traditions), artistic, or applied, practiced by individuals and groups, and control their social and professional relations in the practical or public life. It derives from the skill set, the system of tools, equipment, symbols, rituals, and methods that are used to express these skills. All these systems must interact with each other in the form of an integrated mutual trinity to form a unified overall system or system which gives the people, groups or societies a distinctive complementary character, which is the cultural nature, and they each have their personality or identity, which is the cultural identity.

Second: Leadership Integration, which represents the supreme authority in any organization, whatever its size and size. It manages all its internal and external relations.

Also, the organization's leaders must be distinguished by the following (Nasyira, et al, 2014)

- Excellence in comprehensive knowledge: the process of leadership management and decision-making requiring people and advisors who have comprehensive knowledge that enables them to understand all the variables and their effects, and to form a comprehensive overall picture around it. Without it, decisions taken will not be rational. 
- The availability of wisdom that enables the leadership to use the knowledge and information that is available to it in a way that leads to an effective decision.

- The ability to build reliability or trust in his various relationships and successfully with subordinates and clients who deal with his organization.

- The ability to influence subordinates and obtain their acceptance is acceptance of consent, not an acceptance of submission (Adebayo, 2010, 67-68).

- The ability to resist internal or external pressures aimed at distorting leadership decisions on their objectivity and fairness. (Kim \& Yong, 2005).

- The ability to take responsibility, because without it leadership loses its essence.

Adherence to the ethical values and the system of values accepted in the organization so that the leadership behavior reflects these values, whether it is personal behavior or behavior during work (French, et al.2019, 156).

- The ability to build an aura of a charismatic nature that persuades subordinates and dealers with the leader's personality and capabilities.

- The ability to build role models. Effective leadership is the role model for subordinates ((Alsawalhah Et al, 2015).

Third: Functional Integration: the availability of all the functions that make up the organization's career system, and are administrative, consulting, technical, or administrative auxiliary or general service jobs. With a clear and comprehensive definition of their descriptions and the nature of the functional techniques for each of them, this includes determining the level and types of these technologies. And then define its specifications that determine the competencies that must be met in the incumbents of these jobs. (Nasser \& Saadeh, 2013). In addition to this, it is necessary to determine the different job sizes, in a manner consistent with the organization's mission and strategic directions, taking into account the dimensions and conditions of the competitive environment (Almutairi \& Alsawalhah, 2020). This is done by determining the area of each job, the degree of its breadth or capacity, and then its workload. This depends on the criteria that organizations decide for itself, as well as the criteria that governments may set regarding this. As well as identifying functional levels in a manner consistent with the requirements of institutional culture, whether they are jobs located in the higher, middle, or lower organizational levels, with a definition of sub-levels within each of these levels, if any (Alsawalhah, et al.2013).

Fourth: Structural Integration: It means that all the elements and components that constitute the total entity of the organization are identified, and when they become regular and integral they become the general picture of the organization as a tangible presence. To achieve integration at this level, all of these components must be identified and identified in the light of detailed knowledge of the functional ingredients. The structures are designed to serve the job performance determined by the organization's policies. Structural integration is not achieved if it is not within a process of alignment and balance with the state of functional integration and we can define the structural components as Following: Kehinde, 2012 (Richard, 2008).

- The physical elements that include the organization's land, area, and divisions, and the various installations that the organization needs to exercise its functions and operations, and these installations include from the pencil to the building, or the organization's buildings, and the divisions of these buildings and their various facilities.

The legal (organizational) elements: all components of the legislative hierarchy (from the constitution to the law, regulations, instructions, orders, decisions, and directives) that are relevant to the organization and governs its existence and movement.

- Financial elements: the organization's revenues and expenditures.

- Human elements: the needs of the organization of employees or users classified on a quantitative and qualitative basis according to the needs of each job of the organization (AlShawabkeh, \& Alsawalhah,2019)

\subsection{Effectiveness of the Operational Processes}

Operational processes are defined as the operations that take place within the organization and are focused on the activities and goals that the organization has found to achieve, and thus these processes differ completely from one organization to another according to the nature of the specialty of each organization and what is its mission. Karimi, et al., 2014). It is clear from this that these processes are the backbone of all the other components and processes that make up the organization. Thus, attention should be focused primarily on these processes to 
ensure their effectiveness, and to constantly improve this effectiveness, so that the organization concerned can achieve its mission for which it was created. (Ibrahim, 2014), (Sing, 2011,214). In management, the largest part of operations' inputs comes from operational operations as indicators, results, and dashboards, and also in the form of problems looking for solutions, but their inputs are the views of stakeholders on the other hand (workers, shareholders, partners), and the outputs can be considered goals and organizational directives, plans Work to other (Alsawalhah, A. (2020). It is necessary to analyze an important number of basic elements to get acquainted with the reality of the operational operations in any organization and estimate the level of its effectiveness, to assess the general effectiveness of the organization concerned, and these elements are as follows: (strategic effectiveness, the effectiveness of resources and techniques, the effectiveness of performance and results). (Siddique, et al, 2013).

\subsubsection{The Effectiveness of Operational Process Dimensions}

First: Strategic effectiveness: includes the organization's strategic clarity and understanding of its staff (Goethch $\&$ Stanley, 949, 889, 989). Strategic effectiveness is called key processes. Some goals within the organization are strategic, and this is because they contain key elements in the organization's success. The key process is the process that contributes significantly to reaching strategic goals. Therefore, to define key processes, it must first determine the weight of each process for the strategic goals. The strategic operations also reflect the vision and key factors for the success of the organization, its adaptation to its external environment, and helps to develop it in the medium and long term and enhance its position in the market, and these operations contain important risks if they are neglected in comparison to the rest of the operations (Wallgren, 2011). The operational plans are multiple, and their indicators are varied. The most important factor of these indicators can be identified, as follows: the extent to which the operational goals are clearly defined, the extent to which operational processes are integrated at the organizational unit level, the extent to which operational procedures are clearly defined for operational operations, the ease (simplicity) of executive procedures. The extent of coordination between the various units in the implementation of work procedures, the extent of planning tools and equipment necessary for operation, the extent to which there are a follow-up and evaluation mechanism for operational operations, the extent to which operational goals are absorbed by employees, the extent to which executive lines and procedures are understood by the employee Yen, the extent of mastery in the use of tools and devices used, the extent to which the follow-up and evaluation mechanism is applied to operational processes, the extent to which work is being done to improve and develop operational procedures (Kakkos \& Trivellas, 2011).

\section{Second: The Effectiveness of Resources and Technologies}

It includes the effectiveness of resources and technologies (the effectiveness of operational material resources, the effectiveness of operational financial resources, the effectiveness of operational human resources, the effectiveness of operational operations technology, the effectiveness of the information needed for operation, the effectiveness of the security and safety system for operations) (2010 et al Gunalu).

- Effectiveness of operational material resources includes the availability of tools, equipment, and technologies necessary for operational operations and the extent to which they are available. In addition to the extent to which mechanisms are in place to constantly update tools, equipment, and technologies, the suitability of the working climate and conditions (lighting, ventilation, HVAC, Noise, Cleanliness).

Effectiveness of operational financial resources: this includes the extent of the existence of a plan for operational financial resources, adequacy of operational financial resources, the extent to which there is a mechanism for monitoring and controlling operational expenditures, and the extent of flexibility in spending operations according to operating requirements.

The effectiveness of operational human resources: Human resources are the basis of any vital organization and its intellectual capital. It leads all operational processes and depends on the organization's successes and activities. For any organization to make the best use of these resources, it must carry out an analysis of its reality and identify any gaps in the level of its effectiveness to define the foundations for its development and adapt it in a way that leads to the development of its activities (Al-Raggad\& Alsawalhah, 2017). It also includes the extent of the adequacy of the human resources necessary for the operations of quantity and quality, the extent of employee participation in planning for operations, and the extent to which employees know the work mechanisms and its operational procedures. Furthermore, the extent to which employees are trained in the performance of their work and which work is done to study and overcome work problems, in addition to the competence of employees in carrying out their work (Moshal, 2019,366), (Aarabi, 2013,301).

- Effectiveness of technology of operational processes: this includes the degree of knowledge of the technology used, the degree of training in the technology used, the extent of definition and deepening of 
success factors through the uses of modern technology, the extent of knowledge of the difficulties of introducing technology and ways to overcome them, the degree of satisfaction with the level of technology used.

- The effectiveness of the information needed to operate includes: (Robbins \& Judge, 2020, 186). The extent of availability of the information necessary for effective operation, the extent of work to define and update operational information, the efficiency of operational information, the extent of the existence of integrated and available operational information systems, the extent to which workers are familiarized with the necessary operational information. The effectiveness of the security and safety system for operations: the security and safety conditions for operations are among the most important conditions that organizations of various types and forms have become keen to provide due to the high risks they face and that threaten the security and safety of contemporary organizations, especially organizations that increase their degree of dependence on modern technology. The terms of industrial security and safety, or conditions of security and safety of information and its confidentiality, or conditions of security and safety of the work environment, are considered matters that should be taken care of and precaution in a high-precision manner to avoid any risks that may arise from breaching any of them. (Robbins \& Judge, 2020, 197-198). The most important indicators related to the state of security, safety and security have been identified in the organization, and information has been collected on that and the results have been reached as follows (Emmanuel, et al, 2011): the extent of identifying the risks to performance in the organization, the extent of studying and analyzing the risks and their likelihood of occurring, the extent of the existence of a management plan Risks, the extent of work on reviewing and updating the risk plan, along with updating work tools and techniques, the extent of expected control in the event of crises.

Third: Effectiveness of performance and results: the performance (results) of operational processes.

Any organization always looks to the results of its various operational processes as one of the most important performance indicators. Operations, whatever their results, are measured because the lesson is said in the results. This is something that should be evaluated at the organizational level, and work to evaluate it so that it can be guided in building the best and most sophisticated processes capable of providing better and more qualitative results. (Cuirrin, 2007, 56). The effectiveness of performance and results includes the following: The effectiveness of performance levels, the effectiveness of the amount of performance or results (outputs), the effectiveness of the quality of performance or results and the absence of errors, the extent of satisfaction with the speed of performance and achievements promptly, the extent of satisfaction with the cost of performance (lack of exaggeration in costs). The extent to which the levels of performance or results are consistent with the expected objectives, the extent to which the results are analyzed and evaluated, and the lessons learned are documented (Khan \& Iqbal, 2013, 134).

\section{The Analysis of the Study Data and the Hypothesis Test}

\subsection{Descriptive Analysis of the Questionnaire Data}

9.1.1 Independent Variable: Analysis of Organizational Integration Dimensions

Table 1. The mean and the standard deviation of the organizational integration dimensions

\begin{tabular}{ccccc}
\hline Number & Dimension & The Median & $\begin{array}{c}\text { The Standard } \\
\text { Deviation }\end{array}$ & $\begin{array}{c}\text { The } \\
\text { Arrangement }\end{array}$ \\
\hline $\mathbf{1}$ & Cultural integration & 4.03 & 0.568 & 2 \\
$\mathbf{2}$ & Leadership authority integration & 4.15 & 0.039 & 1 \\
$\mathbf{3}$ & Functional Integration & 3.98 & 0.509 & 3 \\
$\mathbf{4}$ & Structural integration & 3.82 & 0.5 .22 & 4 \\
& The average & 4.06 & & \\
\end{tabular}

The above table indicates the high relative importance of organizational integration in the researched company, where the mean (4.06) and the standard deviation (0.534), and this confirms the tendency of the study sample to agree to the paragraphs and dimensions of the organizational integration variable. 9.1.2 The Variable: The Analysis of the Dimensions of the Effectiveness of Operational Processes 
Table 2. Analysis of the Dimensions of the Effectiveness of Operational Processes

\begin{tabular}{clccc}
\hline Number & Dimensions & The median & $\begin{array}{c}\text { The } \\
\text { Standard } \\
\text { Deviation }\end{array}$ & $\begin{array}{c}\text { The } \\
\text { Arrangement }\end{array}$ \\
\hline 1. & $\begin{array}{l}\text { The effectiveness of the Strategic Plan } \\
\text { The effectiveness of the resources and } \\
\text { techniques }\end{array}$ & 3.86 & 0.568 & 3 \\
3. & $\begin{array}{c}\text { The effectiveness of the performance and } \\
\text { results }\end{array}$ & 3.91 & 0.653 & 2 \\
& $\quad$ The average & 3.92 & 0.725 & 1 \\
\hline
\end{tabular}

The above table indicates the high relative importance of the effectiveness of the operational operations in the researched company, where the mean (3.96) and the standard deviation (0.521), this confirms the tendency of the study sample to agree to the paragraphs and dimensions of the variable of the effectiveness of operational operations.

\subsection{Testing the Hypothesis of the Study}

H01 Main hypothesis: There is no statistically significant effect at the level of significance $(\alpha \leq 0.05)$ of organizational integration (cultural integration, leadership authority integration, functional integration, structural integration) on the effectiveness of operational processes (strategic effectiveness, resource and technology effectiveness, the effectiveness of Performance and results) in Hikma Pharmaceuticals.

Table 3. The Results of the Multiple Regression Test to the Main Hypothesis

\begin{tabular}{|c|c|c|c|c|c|c|c|c|c|}
\hline $\begin{array}{c}\text { The } \\
\text { dependent } \\
\text { variable }\end{array}$ & $\begin{array}{c}\text { The } \\
\text { correlation } \\
\text { coefficient } \\
\text { (R) }\end{array}$ & $\begin{array}{c}\text { The } \\
\text { coefficient of } \\
\text { determination } \\
\text { R2 }\end{array}$ & $\begin{array}{c}\text { Calculated } \\
\text { f value }\end{array}$ & Variable & B & $\begin{array}{c}\text { The } \\
\text { standard } \\
\text { error }\end{array}$ & B & $\mathbf{T}$ & Sig \\
\hline \multirow{4}{*}{$\begin{array}{c}\text { The } \\
\text { effectiveness } \\
\text { of } \\
\text { operational } \\
\text { processes }\end{array}$} & \multirow{4}{*}{0.865} & \multirow{4}{*}{0.748} & \multirow{4}{*}{38.569} & $\begin{array}{c}\text { Cultural } \\
\text { integration }\end{array}$ & 0.365 & 0.042 & 0.328 & 6.651 & 0.000 \\
\hline & & & & $\begin{array}{l}\text { leadership } \\
\text { authority } \\
\text { integration }\end{array}$ & 0.560 & 0.029 & 0.298 & 5.98 & 0.000 \\
\hline & & & & $\begin{array}{l}\text { Functional } \\
\text { Integration. }\end{array}$ & 0.313 & 0.41 & 0.234 & 9.321 & 0.000 \\
\hline & & & & $\begin{array}{c}\text { Structural } \\
\text { integration }\end{array}$ & 0.367 & 0.42 & 0.354 & 10.458 & 0.000 \\
\hline
\end{tabular}

The multiple regression test was used to test the main hypothesis, as the table showed that the strength of the relationship between the independent and dependent variables is strong and this is indicated by the correlation coefficient value $=r(0.865)$. We also note that the calculated value of $\mathrm{F}$ is (38.569) and at a level of significance less than (0.05). The value of the determining factor $\mathrm{r} 2$ is equal to $(0.748)$ and it indicates that the independent variable (organizational integration) explains $(74.8 \%)$ of the variance in the dependent variable the effectiveness of operational operations.

Test Sub- hypothesis:

H01-1: There is no statistically significant effect at the level of $(\alpha \leq 0.05)$ of cultural integration on the effectiveness of operational processes in Hikma Pharmaceuticals. 
Table 4. The impact of cultural integration of the effectiveness of operational processes

\begin{tabular}{|c|c|c|c|c|c|c|c|c|c|}
\hline $\begin{array}{c}\text { The } \\
\text { correlation } \\
\text { coefficient } \\
\text { (R) }\end{array}$ & $\begin{array}{c}\text { The } \\
\text { coefficient of } \\
\text { determination } \\
\text { R2 }\end{array}$ & $\begin{array}{l}\text { Calculated } \\
\text { f value }\end{array}$ & Result & df & $\begin{array}{l}\text { Independent } \\
\text { variable }\end{array}$ & & & & \\
\hline & & & & & & $\beta$ & $\begin{array}{l}\text { The } \\
\text { standard } \\
\text { error }\end{array}$ & $\mathrm{T}$ & Sig \\
\hline 0.690 & 0.504 & 33.651 & rejected & $1-127$ & $\begin{array}{c}\text { cultural } \\
\text { integration }\end{array}$ & 0.567 & 0.038 & 14.763 & 0.000 \\
\hline
\end{tabular}

Table 4 showed that the independent variable had a significant impact on the dependent variable, the value of the correlation coefficient ( $\mathrm{r}$ ) is equal to (0.690), and This indicates the strength of the relationship between cultural integration and the effectiveness of operational operations in Hikma Pharmaceuticals, as can be seen, that the coefficient of determination ( $\mathrm{r} 2$ ) equal to (0.504), which means that cultural integration has interpreted the rate $(50.4 \%)$ of the variation in the effectiveness of operational processes. the calculated $t$ value is (14.763) which is a statistically significant value, Accordingly, we reject the first sub-hypothesis and accept the alternative hypothesis. Thus, meaning there is a statistically significant effect at the level of $(\alpha \leq 0.05)$ of cultural integration On the effectiveness of operational processes in Hikma Pharmaceuticals.

The second sub-test the hypothesis:

H01-2): There is no statistically significant effect at the level of $(\alpha \leq 0.05)$ for leadership authority integration on the effectiveness of the operational processes in Hikma Pharmaceuticals.

Table 5. The impact of the integration of the leadership authority integration on the effectiveness of operational processes

\begin{tabular}{|c|c|c|c|c|c|c|c|c|c|}
\hline $\begin{array}{c}\text { The } \\
\text { correlation } \\
\text { coefficient } \\
\text { (R) }\end{array}$ & $\begin{array}{c}\text { The } \\
\text { coefficient of } \\
\text { determination } \\
\text { R2 }\end{array}$ & $\begin{array}{l}\text { Calculated } \\
\text { f value }\end{array}$ & Result & df. & $\begin{array}{l}\text { Independent } \\
\text { variable }\end{array}$ & & & & \\
\hline & & & & & & $\beta$ & $\begin{array}{l}\text { The } \\
\text { standard } \\
\text { error }\end{array}$ & $\mathrm{T}$ & Sig \\
\hline 0.785 & 0.616 & 28.954 & rejected & $1-127$ & $\begin{array}{l}\text { leadership } \\
\text { authority } \\
\text { integration }\end{array}$ & 0.419 & 0.031 & 19.855 & 0.000 \\
\hline
\end{tabular}

Table 5 showed that the independent variable had a significant impact on the dependent variable, the value of the correlation coefficient (r) is equal to (0.785), and this indicates the strength of the relationship between leadership authority integration and the effectiveness of operational operations in Hikma Pharmaceuticals, as can be seen, that the coefficient of determination (r2) equal to (0.616), which means that the leadership authority integration has interpreted the rate $(61.6 \%)$ of the variation in the effectiveness of operational processes. The calculated $t$ value is (19.855) which is a statistically significant value, Accordingly, we reject the second sub-hypothesis and accept the alternative hypothesis. Thus meaning there is a statistically significant effect at the level of $(\alpha \leq 0.05)$ for leadership authority integration on the effectiveness of the operational processes in the Hikma Pharmaceuticals).

Testing the hypothesis' third subcommittee:

H01-3: There is no statistically significant effect at the level of $(\alpha \leq 0.05)$ for functional integration on the effectiveness of operational processes in Hikma Pharmaceuticals. 
Table 6. The impact of the functional integration of the effectiveness of operational processes

\begin{tabular}{|c|c|c|c|c|c|c|c|c|c|}
\hline $\begin{array}{c}\text { The } \\
\text { correlation } \\
\text { coefficient } \\
\text { (R) }\end{array}$ & $\begin{array}{c}\text { The coefficient } \\
\text { of } \\
\text { determination } \\
\text { R2 }\end{array}$ & $\begin{array}{l}\text { Calculated } \\
\text { f value }\end{array}$ & Result & df. & $\begin{array}{c}\text { Independent } \\
\text { variable }\end{array}$ & & & & \\
\hline & & & & & & $\beta$ & $\begin{array}{c}\text { The } \\
\text { standard } \\
\text { error }\end{array}$ & $\mathrm{T}$ & Sig \\
\hline 0.825 & 0.680 & 31.854 & rejected & $1-127$ & $\begin{array}{l}\text { Functional } \\
\text { Integration }\end{array}$ & 0.521 & 0.039 & 11.864 & 0.000 \\
\hline
\end{tabular}

Table 6 showed that the independent variable had a significant impact on the dependent variable, the value of the correlation coefficient ( $\mathrm{r}$ ) is equal to (0.825), and This indicates the strength of the relationship between Functional Integration and the effectiveness of operational operations in Hikma Pharmaceuticals, as can be seen, that the coefficient of determination $(\mathrm{r} 2)$ equal to $(0.680)$, which means that the Functional Integration has interpreted the rate $(68 \%)$ of the variation in the effectiveness of operational processes. the calculated $t$ value is (11.864) which is a statistically significant value, Accordingly, we reject the third sub-hypothesis and accept the alternative hypothesis. Thus, (There is a statistically significant effect at the level of $(\alpha \leq 0.05)$ for functional integration on the effectiveness of operational processes in Hikma Pharmaceuticals).

(H01-4): There is no statistically significant effect at the level of $(\alpha \leq 0.05)$ of structural integration on the effectiveness of performance and results in Hikma Pharmaceuticals.

Table 7. Highlights the impact of structural integration on the effectiveness of performance

\begin{tabular}{|c|c|c|c|c|c|c|c|c|c|}
\hline $\begin{array}{c}\text { The } \\
\text { correlation } \\
\text { coefficient } \\
\text { (R) }\end{array}$ & $\begin{array}{c}\text { The coefficient } \\
\text { of } \\
\text { determination } \\
\text { R2 }\end{array}$ & $\begin{array}{l}\text { Calculated } \\
\text { f value }\end{array}$ & Result & df. & $\begin{array}{c}\text { Independent } \\
\text { variable }\end{array}$ & & & & \\
\hline & & & & & & $\beta$ & $\begin{array}{c}\text { The } \\
\text { standard } \\
\text { error }\end{array}$ & $\mathrm{T}$ & Sig \\
\hline 0.910 & 0.828 & 29.567 & rejected & $1-127$ & $\begin{array}{l}\text { Structural } \\
\text { integration }\end{array}$ & 0.741 & 0.038 & 14.581 & 0.000 \\
\hline
\end{tabular}

Table 7 showed that the independent variable had a significant impact on the dependent variable, the value of the correlation coefficient ( $\mathrm{r}$ ) is equal to (0.910), and This indicates the strength of the relationship between structural integration and the effectiveness of operational operations in Hikma Pharmaceuticals, as can be seen, that the coefficient of determination ( $\mathrm{r} 2)$ equal to $(0.828)$, which means that the structural integration has interpreted the rate $(82.8 \%)$ of the variation in the effectiveness of operational processes. the calculated $t$ value is (14.581) which is a statistically significant value, Accordingly, we reject sub-hypothesis four and accept the alternative hypothesis. Thus, (There is a statistically significant effect at the level of $(\alpha \leq 0.05)$ of structural integration on the effectiveness of performance and results in Hikma Pharmaceuticals).

\section{Conclusions and Recommendations}

\subsection{Conclusions}

- There is a presence of a high level of importance for the variables of organizational integration and the effectiveness of operational operations of Hikma Pharmaceuticals.

- There is a statistically significant effect at the level $(\alpha \leq 0.05)$ of organizational integration: (cultural integration, leadership authority integration, functional integration, structural integration) on the effectiveness of operational operations in the Hikma Pharmaceuticals.

- There is a statistically significant effect at the level $(\alpha \leq 0.05)$ of cultural integration on the effectiveness of operational processes.

- There is a statistically significant effect at the level $(\alpha \leq 0.05)$ of the leadership integration on the effectiveness of operational operations in Hikma Pharmaceuticals. 
- There is a statistically significant effect at the level $(\alpha \leq 0.05)$ for job integration on the effectiveness of operational operations in Hikma Pharmaceuticals.

- There is a statistically significant effect at the level $(\alpha \leq 0.05)$ of the structural integration on the 9 -effectiveness of the operational operations in Hikma Pharmaceuticals.

\subsection{Recommendations}

- Work on building a comprehensive strategy for organizational development and integration.

- Develop an integrated plan to improve the company's operational processes.

- Develop a work environment that makes employees want to be a part of it.

- Develop the capabilities of workers by building a training plan that increases their knowledge and skills.

\section{References}

Aarabi, m., Subramaniam I., \& Akeel A. (2013). Relationship between motivational and job performance of employees in the Malaysian service industry. Asian Social Science, 9(9), 301-310. https://doi.org/10.5539/ass.v9n9p301

Adebayo, O.O. (2010). Obstetric Nurses, Perspectives of Managers, Leadership Style on Job Satisfaction and Organizational Commitment, University of Phoenix, USA.

Almutairi, M., \& Alsawalhah, A. (2020). The Impact of Strategies Human Resource Management on Organizational Commitment. (An Applied Study on Employees in Jordanian Islamic Banks). Modern Applied Science, 14(4). https://doi.org/10.5539/mas.v14n4p14

Al-Raggad, M. A., \& Alsawalhah, A. A. (2017). The impact of the strategies of resistance to change management on the improvement of worker's performance (Case Study of the Jordanian Telecommunications Companies). Global Journal of Management \& Business.

Alsawalhah, A. (2014). Organization culture and its role in enhancing the competitive advantage (A Case Study of Jordan Hospital). Interdisciplinary Journal of Contemporary Research in Business, 6(1), 176-185.

Alsawalhah, A. (2020). Talent Management Strategy and its Impact on Employee's Development: An Empirical Study on Jordanian Pharmaceutical Companies. Modern Applied Science, 14(5). https://doi.org/10.5539/mas.v14n5p75

Alsawalhah, A. A., Al-Raggad, M. A., \& Aladwan, A. M. (2015). Impact of Transformational Leadership in Reducing Employees Resistance to Organizational Change. International Journal of Business and Social Science, 6 .

Alsawalhah, A., Irtima, H., Zouby, F., \& Shaar, J. (2013). The relationship between Job Stress and Job performance among workers in Alisraa Hospital. Far East Journal of Psychology and Business, 12(2).

AlShawabkeh, R.O., \& Alsawalhah A.A. (2019). Effects of Training Strategies on Employees Performance: A Practical Study in Amman Municipality Jordan.

Ash., K.M Founder, \& Kay., M. (2012). 1501 ways to reward employees. Canada. Thomas Allen \& son limited. E-book.

Assaf, A., \& Alsawalhah, A. (2013). Environmental impacts of working conditions in paint factories workers in the Hashemite Kingdom of Jordan. European Scientific Journal, 9(8).

Assaf, Abdel-Mo'ti. (2014). Theory (I) of administrative excellence: the theory of management in values (the road to globalism). Amman, Wael House for Publishing and Distribution.

Assaf, A., Alsawalhah, A., \& Al-Tarawneh, H. (2013). The process of continuous development (improvement) and its effects on organizational performance in the department of lands and survey. European Scientific Journal, 9(13).

Bartlett, Christopher, A., \& Joshal Sumentra. (1994). Transboundary Administration. Translator Souad Istanbouli, Egyptian Association for the Diffusion of World Knowledge and Culture, Cairo.

Colquit, le pine Wesson. (2018). Organizational Behavior New York, N.Y.: McGraw hill.

Cuirrin, M. (2007). An Empirical Analysis of the Interrelationship Between Motivation and Stress in the Computing Industry. Water ford institute of technology. 
Emmanuel, A., Adom, E., Josephine, B., \& Solomon, F. (2011). Achievement motivation, academic self-concept, and academic achievement among high school students. European Journal of Research and Reflection in Educational Sciences, 2(2), 24-37.

French R., Rayner C., Ress G., \& Rumbles S. (2019). Organizational Behavior (17ed). John Wiley \& Sons, Ltd, new jersey, USA.

Geurts.S. (2008). Job Motivation and Stress Factors, Tilburg university.

Goethch, Davi., \& Stanley Davis. (2019). Introduction to Total Quality Management for Production, Processing and Services (11th ed). Boston, Prentice hall.

Gunalu, Ebru., Mhmet, Aksarayali., \& Nilufer Sahin. (2010). Job Satisfaction and Organizational Commitment of Hotel Managers in Turkey. International Journal of Contemporary Hospitality Management, 22(5), 693-717. https://doi.org/10.1108/09596111011053819

Ibrahim, H. (2014). The relationship between job stress, co-worker support, and organization-bases self-esteem: a survey across different occupations. Journal of Arts, Science \& Commerce, 1(2), 69-78.

Kakkos N., \& Trivellas P. (2011). Investigating the Link between Motivation, Work Stress, and Job Performance. Evidence from the Banking Industry. 8th International conference on enterprise systems, Accounting and logistics (8th ICESAL '11), 408-428, Thassos, Greece.

Karimi R., Binti Omar Z., Alipour F., \& Karimi Z. (2014). The influencing of role overload, role conflict, and role ambiguity on occupational stress among nurses in selected Iranian hospitals. International Journal of Asian Social Science, 4(1), 34-40.

Kehinde, James. (2012). Talent Management-Effect on Organizational Performance, Lagos State University, Nigeria West Africa. Journal of Management Research, 4(2) 146-158.

Khan w., \& Iqbal Y. (2013). Ann Investment of the Relationship Between Work Motivation (Intrinsic and Extrinsic) and Employee Engagement. master thesis, Umea university.

Kim, Woo, Gon, Jerolled K., \& Yong-Ki Lee. (2005). Effect of Service Orientation on Job Satisfaction, Organization Commitment. International Journal of Hospitality Management, 24(3), 1971-193. https://doi.org/10.1016/j.ijhm.2004.05.004

Moshal B.S. (2019). Organizational Theory and Behavior (11 ed). New Delhi, Parwana Bhawan: Ane Books pvt.ltd.

Nasser R., \& Saadeh B. (2013). Motivation for achievement and structural workplace empowerment among Palestinian healthcare professionals, perspectives on global development, and technology. Perspective on Global Development and Technology, 12, 543-560. https://doi.org/10.1163/15691497-12341273

Nasyira, M.N., Othman, M.N., \& Gazali, H. (2014). Predictors of Intention to Stay for Employees of Casual Dining Restaurant in Klang Valley area. International Food Research Journal, 26-45.

Richard, E. \& Boyatzis. (2008). Competencies in the 21st Century. Journal of Management. https://doi.org/10.1108/02621710810840730

Thompson, Michel, \& others. (1997). Theory of Culture. translated by Ali Al-Sawi, World Knowledge Series, No. 223, National Council for Culture, Arts and Letters, Kuwait.

\section{Copyrights}

Copyright for this article is retained by the author(s), with first publication rights granted to the journal.

This is an open-access article distributed under the terms and conditions of the Creative Commons Attribution license (http://creativecommons.org/licenses/by/3.0/). 